reconstitution. Barrett et al. were able to demonstrate that substitution of the reticulocyte non-histone proteins by chicken liver non-histone proteins prevented the transcription of globin sequences. The specificity observed in chromatin reconstitution must therefore be attributed to components of the non-histone protein fraction.

The use of such chromatin reconstitution systems as a functional assay for specific non-histone proteins still however remains a formidable task. This may be simplified somewhat if purified euchromatin fractions can be successfully reconstituted in the same way. (Euchromatin is that fraction of the chromatin thought to be active in transcription in vivo.) Several groups have isolated fractions of chromatin which seem to have many of the properties expected for euchromatin. There has however been, to date, no demonstration that the DNA of such fractions is enriched for the gene sequences which are transcribed in vivo, in the cell of the chromatin's origin.

An interesting study on the nature of the RNA transcribed in vitro from isolated chick myoblast chromatin, by a mammalian RNA polymerase (form B from calf thymus) has recently been reported by Groner et al. (Proc. natn. Acad. Sci. U.S.A., 72, 194; 1975). These authors found that most of the transcribed RNA was of relatively small size (5 to $7 \mathrm{~S}$ ). They demonstrated, by isopycnic gradient centrifugation in $\mathrm{CsCl}$, that a large proportion of this transcribed RNA remained bound to the DNA template. The addition of a polyanion, heparin, to their reaction mixture resulted in an increase in the amount and size of the RNA transcript. The RNA now sedimented as a broad peak (between 5 to $50 \mathrm{~S}$ ) on sucrose density gradients. $\mathrm{CsCl}$ density gradient analysis revealed that the larger RNA had apparently been released from the template. Pulse-chase experiments established that the small, DNA-bound transcript produced in the heparin was a precursor of the larger material made when heparin was added.

A similar effect of heparin on the amount and size of RNA transcribed from chick oviduct chromatin by both mammalian and bacterial polymerase had previously been reported by Cox (Eur. J. Biochem., 39, 49; 1973). In this case the effect was attributed to the inhibitory effect of heparin on nucleases present in the chromatin. Control experiments by Groner et al. showed that the chromatin used in their study was sufficiently free of ribonuclease activity to eliminate this factor as the major effect of heparin. Groner et al. interpret their results as indicating that the small RNA transcripts made in the absence of heparin are transcribed from, and remain bound to singlestranded regions of DNA. The addition of heparin induces a structural change in the template, resulting in the unwinding of longer stretches of DNA. This, in turn, allows production of much longer transcripts, which are presumably displaced from the template by reformation of the DNA duplex. As the authors point out, their interpretation is consistent with the model of chromatin structure where the unwinding of DNA to single-stranded regions is required for specific transcription (Crick, Nature, 234, 25; 1971).

Two problems arise in this interpretation of the data. First, heparin can cause displacement of chromosomal proteins from DNA (see for example Cox, ibid.) and Groner et al. did not determine whether such displacement was caused by the relatively high levels of heparin $\left(2.5 \mathrm{mg} \mathrm{ml}^{-1}\right)$ used in their experiments. Second, a search for single-stranded regions of DNA in chromatin by Levy and Simpson (Nature new biol., 241, 139; 1973) revealed only very low levels (no more than $0.01 \%$ of the DNA). Nevertheless, it may be of interest to apply the approach of Groner et al. to the transcription of reconstituted chromatin. The use of specific cDNAs may make possible a demonstration that heparin (or other polyanions) can cause release of the transcriptional specificity of chromatin. Thus one might perhaps obtain transcription of sequences not normally produced in the cells of the chromatin's origin. Whether the action of heparin is mimicking, in some gross way, the action of specific gene regulators in eukaryote cells, remains to be established. It is however clear that the in vitro reconstitution and transcription of chromatin will continue to be the focus of a great deal of attention in attempts to unravel the intricacies of transcriptional regulation.

\section{Pyroxene geotherm supports plumes}

\section{from Peter J. Smith}

IN spite of their importance, temperatures in the Earth's interior remain uncertain because they are impossible to measure directly and difficult to estimate indirectly. Recently, however, Boyd (Geochim. Cosmochim. Acta, 37, 2533 ; 1973) applied pyroxene geothermometry to ultramafic xenoliths in the kimberlite pipes of Lesotho and derived a temperature-depth curve which could well represent real temperatures in the upper mantle. He used phase equilibria in the enstatite-diopside and enstatitegarnet systems to obtain the equilibration temperature and pressure of xeno- liths containing the mineral assemblage enstatite + diopside + garnet. The resulting geotherm suggests that down to about $160 \mathrm{~km}$ temperature increases with depth in reasonable accord with the extrapolation of the near-surface thermal gradient. But at a depth of about $170 \mathrm{~km}$ the temperature indicated by the pyroxene geotherm begins to rise much more rapidly, increasing by several hundred degrees over a depth of a few tens of kilometres.

It is difficult to imagine that this rapid temperature rise represents steady state behaviour. But if it is transient (with respect to the lithosphere), what causes it? Boyd's own suggestion was shear heating, which would also explain why the xenoliths from below $170 \mathrm{~km}$ are strongly sheared whereas those from above are unsheared. Unfortunately, this hypothesis fails to explain why the intrusions carrying the xenoliths are localised phenomena. A second possibility would be thermal conductivity variation; but the thermal conductivity would have to decrease by a factor of five, a possible but unlikely change.

Parmentier and Turcotte (Earth planet. Sci. Lett., 24, 209; 1975) therefore propose that the increase in geothermal gradient reflects a relatively localised distortion of the normal mantle convection pattern caused by a mantle plume. As they envisage it, cold lithosphere moves over a hot rising plume. The extra heat arriving at the base of the lithosphere would normally be expected to rise up through the lithosphere by conduction. But conduction is slow, so that before the heat has penetrated very far, any particular section of lithosphere will have moved away from the plume zone. The geotherm in the lithosphere will thus hardly be affected by the plume, except near the base. In other words, the lithospheric and asthenospheric geotherms, which are different, remain largely independent of each other; and this accounts for the point of inflection at about $170 \mathrm{~km}$ (although the small amount of conduction into the lithosphere ensures that the two geotherms merge smoothly). By the same token, the depth at which the temperature begins to rise rapidly is the lithosphereasthenosphere boundary.

Numerical studies of a model involving a cylindrical plume heated from below give results which are consistent with this view. That is to say, the total geotherm predicted from the model is in good agreement with Boyd's pyroxene geotherm as long as the kimberlite intrusion in the model is located away from the plume axis in the direction from which the lithosphere is approaching. Clearly this agreement may be taken as indirect evidence in favour of the existence of mantle plumes. 